\title{
Desain Kontroler Proporsional Modifikasi pada Motor Servo
}

\author{
Abdul Hadi \\ Jurusan Teknik Elektro \\ Politeknik Negeri Bengkalis \\ abdulhadi@polbeng.ac.id
}

\begin{abstract}
Abstrak - Penerapan metode kontroler konvensional seperti kontroler Proporsional pada sistem motor servo didasarkan pada banyaknya kontrol cerdas namun masih belum mampu dalam skala implementasi terkait dengan keterbatasan sistem. Metode Kontrol Proporsional yang umum digunakan menghasilkan keluaran yang memiliki error yang relatif besar. Oleh karena itu, penelitian ini mengajukan metode kontrol proporsional modifikasi untuk mengontrol posisi pada motor servo. Penelitian ini bertujuan untuk menghasilkan keluaran sistem berdasarkan parameter error steady state dan Root Mean Square Error (RMSE). Penelitian ini dibuktikan dengan menganalisa diagram blok penerapan sistem kontroler proporsional modifikasi terhadap sistem orde satu. Selanjutnya, dilakukan analisa gain kontroler proporsional dan gain modifikasi untuk mendapatkan tuning parameter yang sesuai dengan spesifikasi yang diinginkan. Dari hasil eksperimen menggunakan tiga sinyal uji diatas, dapat disimpulkan bahwa kontroler proporsional modifikasi mampu mempercepat respon terbukti dengan nilai delay time sebesar 0,1 detik. Selanjutnya untuk kontrol posisi motor servo, metode kontroler proporsional modifikasi terbukti mampu mengikuti perubahan posisi pada masukan linear dan nonlinear. Pada masukan linear memiliki nilai RMSE 1,1561 dan masukan nonlinear memiliki RMSE yaitu 2,5913.
\end{abstract}

Keyword : Kontrol Proporsional Modifikasi, RMSE, Error Steady State

\section{PENDAHULUAN}

Penerapan metode kontroler konvensional seperti kontroler Proporsional pada sistem motor servo didasarkan pada banyaknya kontrol cerdas namun masih belum mampu dalam skala implementasi terkait dengan keterbatasan sistem [1]. Sistem kontrol cerdas seperti neural network ataupun kombinasinya masih belum mengarah kepada implementasi sistem riil [2][3]. Metode kontroler proporsional ini sangat mudah diterapkan karena sinyal kontrol akan sebanding dengan besarnya kesalahan sistem. Metode Kontrol Proporsional yang umum digunakan menghasilkan keluaran yang memiliki error yang relatif besar.

Penelitian ini mengajukan metode kontroler proporsional modifikasi pada motor servo, dimana pada penelitian sebelumnya masih terdapat kekurangan terutama masih besarnya error yang diperoleh [1]. Hal ini dikarenakan tuning parameter kontroler masih menggunakan metode trial and error. Tuning parameter semakin ilmiah jika dilakukan dengan menggunakan analisa gain [4]. Selain itu, metode kontroler proporsional yang standard tidak akan mampu menghasilkan respon keluaran dengan error menuju ke nol. Penelitian ini bertujuan untuk menghasilkan metode kontroler yang mampu menghasilkan keluaran sistem memiliki kesalahan error steady state dan Root Mean Square Error (RMSE) semakin kecil bahkan menuju ke nol [5]. Penelitian ini dibuktikan dengan menganalisa diagram blok penerapan sistem kontroler proporsional modifikasi terhadap sistem orde satu seperti Gambar 1. Selanjutnya, dilakukan analisa gain kontroler proporsional dan gain modifikasi untuk mendapatkan tuning parameter yang sesuai dengan spesifikasi yang diinginkan. Eksperimen dilakukan dengan menguji dengan input linear dan nonlinear. Pada input linear akan dianalisa delay time dan rise time dan pada input nonlinear dianalisa performasinya menggunakan RMSE.

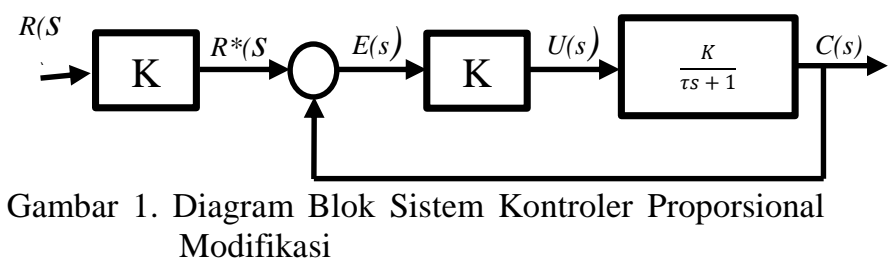

Gambar 1 diatas menggambarkan diagram blok sistem kontrol proporsional modifikasi pada sistem orde satu. $R(s)$ merupakan referensi dan $R^{*}(s)$ merupakan keluaran referensi setelah melewati gain kontroler proporsional modifikasi (Kp2). Kpl merupakan gain kontroler proporsional dengan keluaran kontroler berupa $U(s)$ dan 
keluaran sistem yang dikontrol yaitu $C(s)$. Bentuk modifikasi dari kontroler proporsional umumnya yaitu tambahan gain pada bagian referensi tersebut $(K p 2)$.

\section{METODE KONTROLER}

Dari Gambar 1 diatas menggambarkan diagram blok sistem kontrol proporsional modifikasi yaitu terdapat dua gain atau parameter kontroler yaitu Kpl dan Kp2. Fungsi alih dari diagram blok tersebut diperoleh pada Persamaan (6) jika diketahui Persamaan (1), (2) dan (3) berikut.

$$
\begin{aligned}
& R^{*}(s)=R(s) K p_{2} \\
& E(s)=R^{*}(s)-C(s) \\
& C(s)=E(s) K p_{1}\left(\frac{K}{\tau s+1}\right)
\end{aligned}
$$

Substitusi Persamaan (1) ke Persamaan (2) diperoleh persamaan (4)

$$
E(s)=R(s) K p_{2}-C(s)
$$

Selanjutnya, substitusikan Persamaan (4) ke Persamaan (3) diperoleh Persamaan (5)

$$
C(s)=\frac{R(s) K p_{2} K p_{1}\left(\frac{K}{\tau s+1}\right)}{1+K p_{1}\left(\frac{K}{\tau s+1}\right)}
$$

Dari Persamaan (5) diperoleh fungsi transfer diagram blok Gambar 1 seperti pada Persamaan (6)

$$
\frac{C(s)}{R(s)}=\frac{K p_{2} K p_{1}\left(\frac{K}{\tau s+1}\right)}{1+K p_{1}\left(\frac{K}{\tau s+1}\right)}
$$

Dari Persamaan (6) diperoleh seperti Persamaan (7) yaitu dengan diasumsikan $1=\frac{\tau s+1}{\tau s+1}$.

$$
\frac{C(s)}{R(s)}=\frac{K p_{2} \frac{K p_{1} K}{1+K p_{1} K}}{\frac{\tau}{1+K p_{1} K} s+1}
$$

Jika diasumsikan, $K p_{2}$ seperti pada Persamaan (8), maka diperoleh Persamaan (9) yang menggambarkan fungsi transfer orde pertama keluaran respon sistem yang dikontrol dengan metode Proporsional Modifikasi.

$$
K p_{2}=\frac{1+K p_{1} K}{K p_{1} K}
$$

Sehingga,

$$
\frac{C(s)}{R(s)}=\frac{1}{\frac{\tau}{1+K p_{1} K} s+1}
$$

Diasumsikan $\tau^{*}$ seperti pada Persamaan (10) akan menghasilkan Persamaan (11) berikut ini.

$\tau^{*}=\frac{\tau}{1+K p_{1} K}$

$\frac{C(s)}{R(s)}=\frac{1}{\tau^{*} s+1}$

Jika sistem diberikan masukan step, $\mathrm{r}(\mathrm{t})=\mathrm{u}(\mathrm{t})$ menjadi $R(s)=\frac{1}{s}$, maka besarnya error steady state merupakan selisih antara referensi dengan keluaran sistem seperti pada Persamaan (12).

$e_{s s}=R(s)-C(s)$

Dimana keluaran $C(s)$ adalah keluaran sistem hasil pada keadaan steady state dan $R(s)$ adalah masukan sistem hasil pada keadaan steady state dengan Persamaan (13) dan (14).

$$
\begin{aligned}
& R(s)=\lim _{s \rightarrow 0} s R(s)=\lim _{s \rightarrow 0} s\left(\frac{1}{s}\right)=1 \\
& C(s)=\lim _{s \rightarrow 0} s C(s)=\lim _{s \rightarrow 0} s\left(\frac{1}{s\left(\tau^{*} s+1\right)}\right)=1
\end{aligned}
$$

Sehingga diperoleh Persamaan (15).

$$
e_{s s}=R(s)-C(s)=1-1=0
$$

Dari Persamaan (15) dapat diperoleh bahwa plant sistem orde pertama yang dikontrol dengan metode kontrol Proporsional Modifikasi menghasilkan error steady state bernilai nol.

Untuk menghasilkan gain kontroler proporsional $\left(K p_{1}\right)$, diperoleh melalui Persamaan (10) dimana ditulis ulang dengan bentuk Persamaan (16).

$$
\begin{aligned}
& 1+K p_{1} K=\frac{\tau}{\tau^{*}} \\
& K p_{1}=\frac{1}{K}\left(\frac{\tau}{\tau^{*}}-1\right)
\end{aligned}
$$

Jadi, gain kontroler proporsional $\left(K p_{l}\right)$ diperoleh dari Persamaan (17), sedangkan gain modifikasinya $\left(K p_{2}\right)$ diperoleh dari Persamaan (8).

\section{ANALISA METODE KONTROLER}

Penerapan kontroler proporsional digunakan untuk mengontrol motor servo dengan menggunakan fungsi alih dari penelitian (Erista, 2012) [6]. Bentuk sistem kontrol Proporsional Modifikasi untuk fungsi alih yang dikontrol dapat dilihat pada Gambar 2.

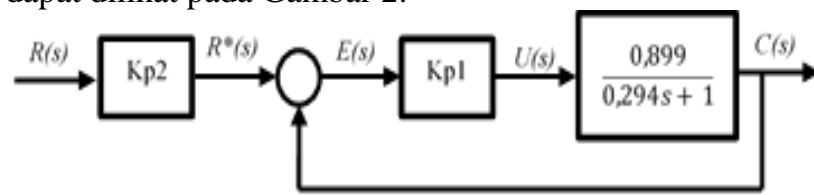

Gambar 2. Sistem Kontrol Proporsional Modifikasi dengan Plant 
Dari Gambar 2 diatas, $K p_{1}$ merupakan gain kontroler proporsional dan Kp2 merupakan tambahan sebagai bentuk gain modifikasi. Eksperiment dilakukan dengan mendesain gain kontroler proporsional $\left(K p_{1}\right)$ dan gain modifikasi $\left(K p_{2}\right)$ yang berhubungan dengan time constant. Dari Gambar (2) pada bagian plant digambarkan pada Persamaan (18) dimana diperoleh Persamaan (19) dan (20).

$$
\begin{aligned}
& G(s)=\frac{0,899}{0,294 s+1} \\
& K=0,899 \\
& \tau=0,294
\end{aligned}
$$

Desain kontroler proporsional modifikasi ini berhubungan dengan time constant respon keluaran yang diinginkan.

Pada desain ini diinginkan time constant hasil desain $\left(\tau^{*}\right)$ tiga kali lebih cepat dari time constant $(\tau)$ semula, sehingga berlakulah Persamaan (21) dan diperoleh Persamaan (22).

$$
\begin{aligned}
& 3 \tau^{*}=\tau \\
& \tau^{*}=\frac{0,294}{3} \text { detik }
\end{aligned}
$$

Dengan diinginkan hasil desain memiliki time constant respon keluaran tiga kali lebih cepat dari time constant semula diperoleh seperti Persamaan (22).

Setelah diperoleh $\tau^{*}$ seperti pada Persamaan (22), maka diperoleh Gain Kontroler Proporsional $\left(K p_{l}\right)$ dan Gain Modifikasi $\left(\mathrm{Kp}_{2}\right)$ menggunakan Persamaan (17) dan (8) yaitu pada Persamaan (23) dan (24).

$$
\begin{aligned}
K p_{1} & =\frac{0,588}{0,264306} \\
K p_{2} & =\frac{0,208018865628}{0,138161203992}
\end{aligned}
$$

Dari hasil desain diatas diperoleh $K p_{1}$ dan $K p_{2}$, dimana hasil ini akan dibuktikan dengan berdasarkan simulasi.

\section{HASIL DAN PEMBAHASAN}

Simulasi pengujian akan dilakukan dengan tiga jenis sinyal uji yaitu fungsi step, ramp dan sinusoidal. Sinyal fungsi step digunakan untuk membuktikan ketercapaian delay time dan rise time dari desain yang dihasilkan. Pada sinyal step ini akan diberikan setpoint sebesar 100 dimana step time dari nol dengan durasi simulasi 4 detik. Sinyal uji selanjutnya yaitu sinyal Ramp dimana digunakan untuk menguji sistem motor servo ketika diberi setpoint linear. Sinyal uji step ini dimasukkan dengan kemiringan (slope) sebesar 2 dengan durasi simulasi 10 detik. Sinyal uji ketiga yaitu sinyal sinusoidal dimana digunakan untuk menguji sistem motor servo ketika diberi setpoint nonlinear. Sinyal sinusoidal ini dimasukkan dengan besar amplitudo $1 \mathrm{~cm}$ dan frekuensi $6,28 \mathrm{rad} / \mathrm{s}$ atau sama dengan $1 \mathrm{Hertz}$ dengan durasi simulasi 4 detik. Pada sinyal uji linear dan nonlinear ini akan dinilai besar kesalahan melalui besaran Root Mean Square Error (RMSE) seperti pada Persamaan (25).

$$
R M S E=\sqrt{\sum_{i=1}^{N}(E)^{2}}
$$

Desain yang diinginkan yaitu berhubungan dengan time constant. Time constant desain pada respon keluaran setelah dikontrol diinginkan 3 kali lebih cepat daripada time constant semula. Sehingga diperoleh hasil seperti pada Persamaan (23) nilai $K p_{1}=\frac{0,588}{0,264306}$ dan Persamaan (24) nilai $K p_{2}=\frac{0,208018865628}{0,138161203992}$.

Pengujian yang pertama menggunakan sinyal step untuk membuktikan sistem kontrol proporsional modifikasi mencapai delay time dan rise time, sehingga diperoleh seperti pada Gambar (3) berikut ini.

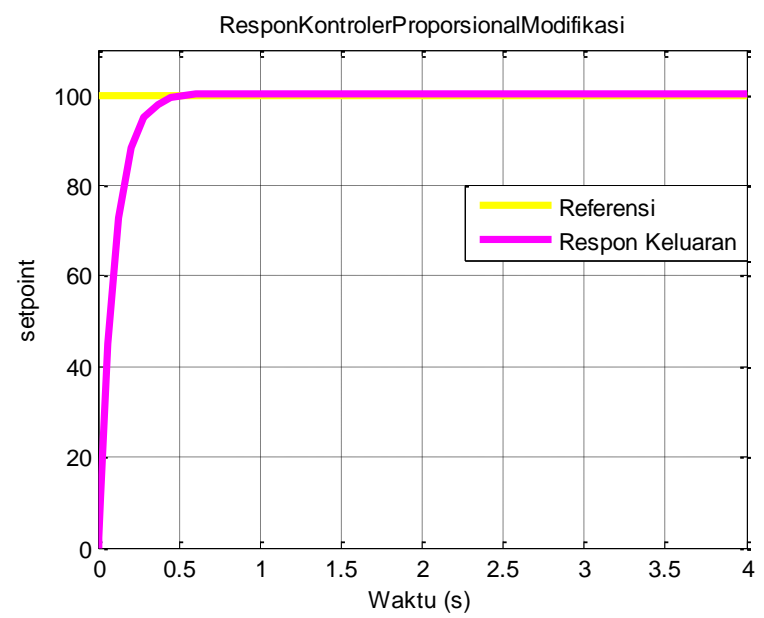

Gambar 3 : Respon Referensi dan Keluaran dengan Sinyal Uji Step

Dari Gambar (3) diatas diperoleh delay time pada 0,1 detik dan rise time pada 0,5 detik. Dari hasil eksperimen ini membuktikan kontroler proporsional modifikasi mampu mempercepat respon tiga kali lebih cepat dari time constant semula yaitu 0,294 detik.

Pengujian yang kedua yaitu menggunakan sinyal Ramp untuk membuktikan sistem kontrol proporsional modifikasi untuk mengontrol posisi motor servo pada kontur Linear, seperti pada Gambar (4) berikut ini. 


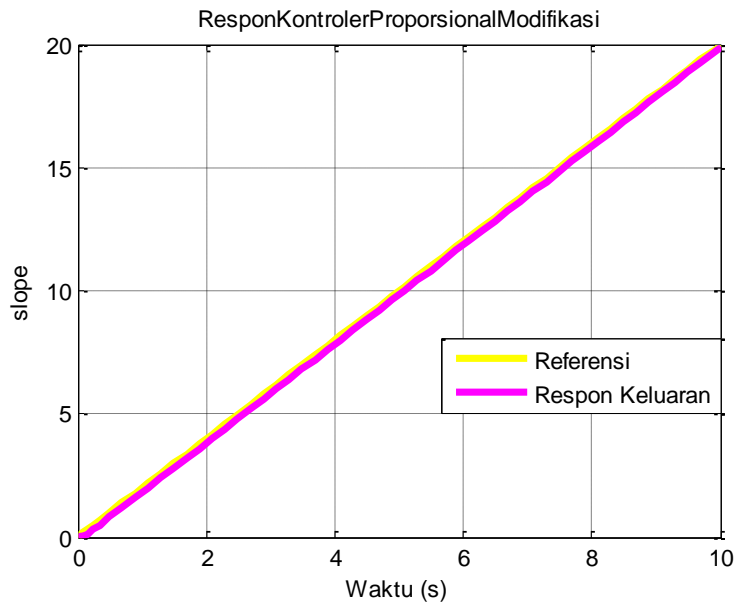

Gambar 4 : Respon Referensi dan Keluaran dengan Sinyal Uji Ramp

Dari Gambar (4) di atas membuktikan posisi motor servo yang dikontrol dengan metode kontroler proporsional modifikasi respon keluaran mampu mengikuti referensi yang diberikan dengan nilai RMSE yaitu 1,1561.

Pengujian yang ketiga yaitu menggunakan sinyal Sinusoidal untuk membuktikan sistem kontrol proporsional modifikasi mengontrol posisi motor servo pada kontur Nonlinear, seperti pada Gambar (5) berikut ini.

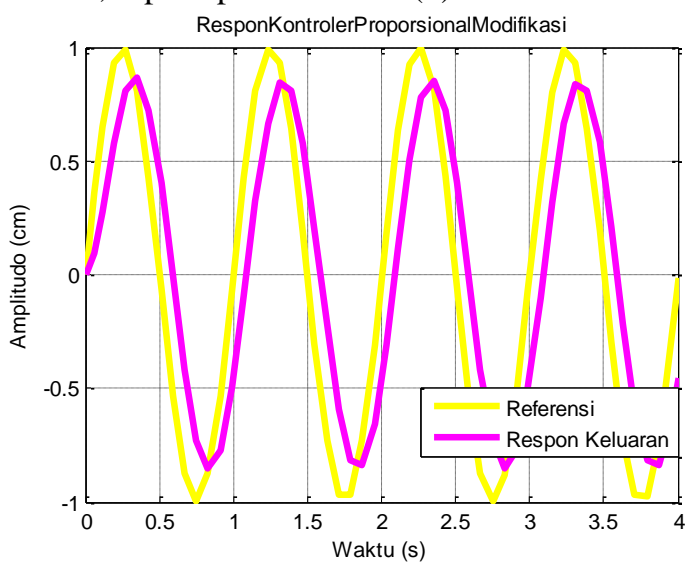

Gambar 5 : Respon Referensi dan Keluaran dengan Sinyal Uji Sinusoidal

Berdasarkan Gambar (5) diatas membuktikan posisi motor servo yang dikontrol dengan metode kontroler proporsional modifikasi mampu mengikuti referensi yang diberikan dimana nilai RMSE yaitu 2,5913.

\section{KESIMPULAN}

Dari hasil eksperimen menggunakan tiga sinyal uji diatas, dapat disimpulkan bahwa kontroler proporsional modifikasi mampu mempercepat respon terbukti dengan nilai delay time sebesar 0,1 detik. Selanjutnya untuk kontrol posisi motor servo, metode kontroler proporsional modifikasi terbukti mampu mengikuti perubahan posisi pada masukan linear dan nonlinear. Pada masukan linear memiliki nilai RMSE 1,1561 dan masukan nonlinear memiliki RMSE yaitu 2,5913.

\section{DAFTAR PUSTAKA}

[1] A. Hadi, Kontrol Proporsional untuk Motor Servo, Prosiding Seminar Nasional Industri dan Teknologi (SNIT), Politeknik Negeri Bengkalis, Bengkalis 2016.

[2] Syafaah, L., Suhardi, D., \& Pakaya, I. (2016). Kontrol Proportional-Integral (PI) Optimal Pada Motor Servo DC Menggunakan Algoritma Particle Swarm Optimization (PSO). Research Report, 613618.

[3] E. A. Ebrahim, A Novel Approach of an Adaptive Neuro-PI Vector Controller Fed Induction Motor Servo, Proceedings of the IEEE/RSJ of International Conference on Intelligent Robots and Systems, Switzerland, 2002.

[4] A, Hadi, Perbandingan Tuning Parameter Kontroler PD menggunakan Metode Trial And Error dengan Analisa Gain pada Motor Servo AC, Jurnal Inovasi dan Teknologi (Inovtek) Vol 6 No. 1, 2016.

Chal, T dan Draxler, R. R., Root mean square error (RMSE) or mean absolute error (MAE) - Arguments against avoiding RMSE in the literature, Published in Geosci. Model Dev. Discuss.:, 2014.

[6] Safitri, E, B, dkk., Implementasi Kontroler P-PI Kaskade untuk Meningkatkan Keakuratan Mesin Bubut CNC . JURNAL TEKNIK ITS Vol 1. F75-F80, 2012. 